\title{
Evaluation of Coconut (Cocos nucifera) Husk Fibre as a Potential Reinforcing Material for Bioplastic Production
}

\author{
Omoniyi A. Babalola ${ }^{1, a}$ and Abel O. Olorunnisola ${ }^{2, b^{*}}$ \\ ${ }^{1}$ Department of Agricultural \& Environmental Engineering, University of Ibadan, Nigeria \\ ${ }^{2}$ Department of Wood Products Engineering, University of Ibadan, Nigeria \\ aniyibarbz@gmail.com, babelolorunnisola@yahoo.com
}

Keywords: coconut husk, bioplastic, cassava starch, biodegradable materials

\begin{abstract}
In this study the potential use of coconut husk (Cocos nucifera) husk fibre for the reinforcement of bio-plastic produced with cassava (Manihot utilissima) starch was investigated. Five compositions of the bioplastics were formulated containing $0 \%$ (control), 5\%. 10\%, 15\% and $20 \%$ of coconut husk fibre. The tensile strength, modulus of elasticity, impact energy, water absorption, and biodegradability of the fibre-reinforced bioplastic samples were then determined in accordance with standard methods. Results obtained showed that the tensile strength values ranged from 0.36 to $0.68 \mathrm{MPa}$; while the modulus of elasticity ranged from $2.7 \times 10^{6}$ to $4.9 \times 10^{6}$ $\mathrm{N} / \mathrm{m}^{2}$. The impact energy range was 1.73 - $3.7 \mathrm{~J}$. Analysis of variance showed that coconut husk fibre content had a significant effect on the tensile strength. The impact energy increased with an increase in fibre content up to $15 \%$. Also, water absorption (27.3 - 42.9\%) increased with an increase in fibre content. The bioplastics were biodegraded within one month of grave yard test. The optimum fibre reinforcement level was found to be $10 \%$. This may, however, be increased to $15 \%$ for impact resistance improvement.
\end{abstract}

\section{Introduction}

Plastic is a material consisting of a wide range of synthetic or semi-synthetic organics that are malleable and can be moulded into solid objects of diverse shapes. Plastics are used in an enormous and expanding range of products due to their long life and attractive properties including relatively low cost, ease of manufacture, versatility, and imperviousness to water. The world's annual consumption of plastic materials has increased from around 5 million tons in the 1950s to nearly 100 million tons; thus, 20 times more plastic is produced today than 50 years ago [1]. This implies that on one hand, more resources are being used to meet the increased demand for plastics, and on the other hand, more plastic waste is being generated. Most of the plastic waste is neither collected properly nor disposed of in appropriate manner to avoid its negative impacts on the environment and public health in many African countries. Due to extremely long periods required for their natural decomposition, waste plastic is often the most visible component in waste dumps and open landfills.

The increased use of synthetic plastics in developing countries is a particular concern as their waste management infrastructure are seldom able to deal effectively with the increasing levels of plastic waste [2,3]. In spite of this daunting challenge, however, the use of plastics has significantly replaced leaves, glasses and metals as a cheaper and more efficient means of packaging in many African societies, except in Kenya and few other countries that have recently banned the use plastic bags in shops and supermarkets.

A group of more environmental friendly alternative materials worthy of consideration in Africa is collectively known as bio-plastics, i.e., plastics derived from renewable biomass 
sources, such as vegetable fats and oils, corn starch, straw, woodchips, food waste, etc. Bioplastics have been used in a variety of consumer products, such as food containers, grocery bags, biodegradable utensils, and food packaging. These are called commodity plastics. Bioplastics can, however, also be used for engineering grade applications, such as electrical and electronic housings and enclosures. The greatest advantages of bioplastics are a smaller carbon footprint and a less polluted ecosystem. The problem of overflowing landfills and floating islands of trash in Africa may be addressed through increased use of bioplastics.

Starch and cellulose are two of the most common renewable feedstocks used to create bioplastics and these typically come from corn and sugarcane. In Nigeria, cassava starch is of interest as a candidate for producing bioplastics, given the fact that Nigeria is the largest producer of cassava (tapioca) in the world, accounting for up to $20 \%$ of the global, about 34\% of Africa's and about $46 \%$ of West Africa's cassava production. Annual production in 2017 was conservatively put at 50,000 metric tonnes [4]. It has been shown that reinforcement of bioplastics with a natural fibre may enhance the tensile strength [5]. The typical biofibre sources for bioplastics include cotton, flax or hemp, recycled wood, waste paper, crop processing byproducts, etc. However, a major potential reinforcement material in Nigeria is coconut (Cocus nucifera) husk fibre which has relatively high tensile strength, is available in abundant quantities, but largely treated as a waste material [6,7]. Nigeria produces about 267,500 metric tonnes of coconuts annually and the country occupied the $18^{\text {th }}$ position on the world coconut production index as at 2017 [8].

There are two types of coconut fibres, i.e., brown fibre extracted from matured coconuts and white fibres extracted from immature coconuts. Brown fibres are thick, strong and have high abrasion resistance, while white fibres are smoother and finer but weaker. There are many general advantages of brown coconut husk fibres, the object of this study: they are moth-proof, resistant to fungi and rot, provide excellent insulation against heat and sound, not easily combustible, flame-retardant, unaffected by moisture and dampness, tough and durable, resilient, springs back to shape even after constant use, totally static free, and easy to clean [8].

The aim of this study was to investigate the effects of coconut fibre reinforcement on selected properties of a cassava starch-based bioplastic.

\section{Methodology}

Bioplastic specimens (a sample is shown in Figure 1) were produced with cassava starch and varied coconut husk fibre contents of 0, 5, 10, 15 and 20\% (by weight). The fibres were cut into $2 \mathrm{~mm}$ length followed by chemical treatment to reduce lignin and hemi-celluloses contents involving soaking in 1 molar solution of $\mathrm{NaOH}$ at $50^{\circ} \mathrm{C}$ for 4 hours. The fibres were then washed, dried at $80^{\circ} \mathrm{C}$ in an oven and mixed with cassava starch, water, glycerin and acetic acid in predetermined proportions in a container. The blended mixture was then transferred to a mould, heated up to $65^{\circ} \mathrm{C}$ for $4 \mathrm{~h}$ and air cooled at room temperature. Tensile test was performed using $3 \mathrm{~mm}$ thick dog-bone shaped specimens. Three replicate samples were tested for each composition at a fixed crosshead speed of $5 \mathrm{~mm} / \mathrm{min}$ in accordance with ASTM D638 standard test methods for plastic properties in tension. 


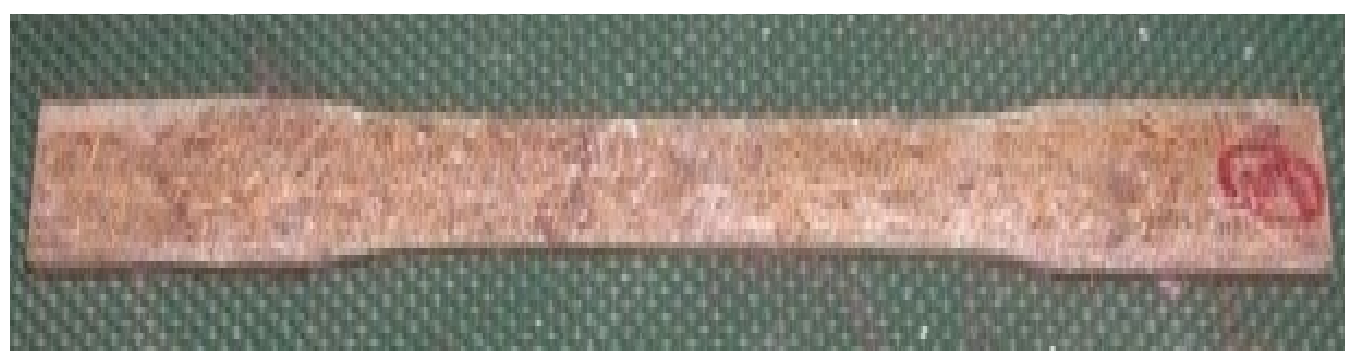

Fig. 1: A sample of the coconut husk fibre-reinforced bioplastic

Impact resistance tests were performed on $60 \times 60 \times 2 \mathrm{~mm}$ specimens using an adaptation of ISO 6603-1. A known weight of $0.616 \mathrm{~kg}$ was raised to a known height and allowed to fall on each specimen. The height travelled by the ball when the first visible crack had developed on the face was recorded. The total energy of fracture was determined using equation 1 :

$$
\mathrm{T}=\mathrm{mgh} .
$$

Where $\mathrm{T}$ is the total energy, $\mathrm{m}$ is the mass, $\mathrm{g}$ is the gravitational acceleration, and $\mathrm{h}$ is the height.

Water absorption properties were determined by weighing samples in air before and after immersion in water for 24 hours. The percentage amount of water absorbed by samples was calculated using equation 2:

$$
\mathrm{W}(\%)=\frac{W t-W o}{W o} \times \frac{100}{1} .
$$

Where $W$ is percent water absorption, Wo and $W t$ are the initial and final masses of the specimen before and after immersion in water respectively.

Biodegradability of the samples was determined using the standard grave yard test that involved burying the samples in a soil at a depth of about $900 \mathrm{~mm}$ for one month. The degree of biodegradation was monitored for a period of one month.

\section{Results and Discussion}

\section{Tensile strength}

Table 1 shows the tensile strength values of the bioplastics reinforced with coconut husk fibres at different levels. The values obtained were relatively low compared to those reported for bioplastics produced with cassava starch and reinforced with recycled newspaper pulp [9]. Also, the tensile strength increased as the coconut husk fibre content increased from 0 to $10 \%$, but decreased thereafter. The significant increase $(\mathrm{p}<0.05)$ in tensile strength $(0.36$ to $0.68 \mathrm{MPa})$ in the 5 to $10 \%$ fibre content ranges was most likely a result of good interaction between the coir fibre and matrix and a strong interface created which led to a strong bonding as noted in previous studies $[9,10]$. 
Table 1: Tensile Strength of the Bioplastic Specimens

\begin{tabular}{ccc}
\hline Specimen & $\begin{array}{c}\text { Mean Tensile Strength } \\
{\left[\mathrm{N} / \mathrm{m}^{2}\right]}\end{array}$ & $\begin{array}{c}\text { Elastic Modulus } \\
{\left[\mathrm{x} 10^{5} \mathrm{~N} / \mathrm{m}^{2}\right]}\end{array}$ \\
\hline 0\% fibre content & 0.36 & 26.7 \\
5\% fibre content & 0.62 & 42.7 \\
10\% fibre content & 0.68 & 49.1 \\
15\% fibre content & 0.45 & 33.4 \\
20\% fibre content & 0.37 & 33.2 \\
\hline
\end{tabular}

\section{Elastic Modulus}

As shown in Table 1, modulus of elasticity of the bioplastics ranged from $26.7 \times 10^{5}$ to $49.1 \mathrm{x}$ $10^{5} \mathrm{~N} / \mathrm{m}^{2}$. These values are quite high, suggesting that the material a lot of stress with minimal strain. Again, as the coconut husk fibre content increased up to $10 \%$, the modulus of elasticity also increased significantly perhaps due to the good interaction between the coir fibre and matrix. Beyond this point, there was a considerable decrease in modulus of elasticity attributable to relatively poor interface between the fibre and the matrix.

\section{Impact Resistance}

The impact test results are presented in Table 2. The values ranged from 1.73 to $3.7 \mathrm{~J}$. The relatively low impact resistance suggests that the material may not be used in applications where impact resistance is critical such as electrical and electronic housings and enclosures.

Table 2: Impact Resistance of the Bioplastics

\begin{tabular}{cc}
\hline SAMPLES & MEAN IMPACT ENERGY \\
& {$[\mathrm{J}]$} \\
\hline 0\% fibre content & 1.7308 \\
5\% fibre content & 2.3948 \\
10\% fibre content & 2.9381 \\
15\% fibre content & 3.7024 \\
20\% fibre content & 3.6420 \\
\hline
\end{tabular}

However, the impact resistance increased significantly with increasing coconut husk fibre content up to 15 , an indication of the fact that $15 \%$ is about the upper limit of the quantity of fibre that could be incorporated in the bioplastics to improve their desirable properties.

\section{Water absorption}

The water absorption (WA) after 24hrs for the different bioplastic specimens is shown in Figure 2. The values ranged between 27.2 and $42.9 \%$. These values are much lower than the WA values reported for bioplastics produced with cassava starch and reinforced with recycled newspaper pulp [9], but higher than the WA values reported for polypropylene reinforced with alkalinetreated coconut husk fibres [10]. However, in line with a previous finding on polypropylene reinforced with alkaline-treated coconut husk fibres, but contrary to another finding cassava starch-based bioplastics reinforced with recycled newspaper, the control samples (without fibre reinforcement) had the lowest WA and the WA increased with increasing fibre content. The behaviour of the bioplastic specimens tested in this study is, perhaps, due to micro void creation in the matrix with the introduction of the coconut husk fibres and/or the hydrophilic nature of fibre $[5,11]$. 


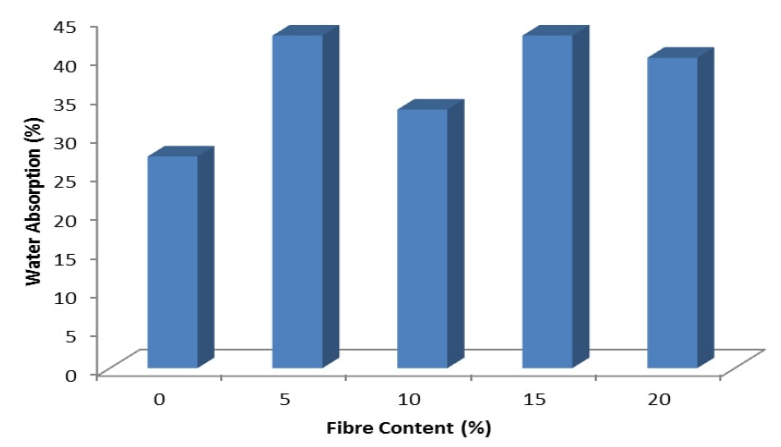

Figure 6: Mean water absorption of the bioplastic specimens

\section{Biodegradability}

A complete degradation of all the bioplastic samples was observed after one month burial in the soil, indicating that the material is biodegradable and can be used in a variety of consumer products, such as food containers, grocery bags, biodegradable utensils, and food packaging. Technically, all materials are biodegradable, but not all bio-based plastics are biodegradable. For practical purposes, only bioplastics that degrade within a relatively short period of time (weeks to months) are usually considered biodegradable; those that do not degrade within a few months or years are said to be durable [12].

\section{Conclusion}

It was concluded that coconut husk fibre could be used as reinforcement in a cassava starchbased bioplastic. An an inclusion of up to $10 \%$ of coconut husk fibre could result in significant improvement in the tensile strength and modulus of elasticity. The fibre quntity may, however, be increased to $15 \%$ for impact strength improvement.

\section{References}

[1] United Nations Environmental Programme, Developing integrated solid waste management plan. Training manual volume 3: Targets and issues of concern for ISWM. UNEP, Nairobi, Kenya, 2009.

[2] W.R. Yu, B.H. Lee, H.J. Kim, Fabrication of long and discontinuous natural fibre reinforced polypropylene biocomposites and their mechanical properties, Fibres and Polymers 10-1 (2009) 83-90. https://doi.org/10.1007/s12221-009-0083-z

[3] Information on http://www.onlinesciences.com/health/danger-and-bad-effects-of-burningplastics-and-rubber-on-humans-and-global-warming.

[4] Information on http://www.fao.org/nigeria.

[5] F.U. Felix, A. Adetifa, Characteristics of kenaf fiber-reinforced mortar composites. IJRRAS 12-1 (2012) 18-26.

[6] R.D. Filho, N.P. Barbosa, K. Ghavami, Application of sisal and coconut fibres in adobe blocks. In: HS Sobral (ed.), Vegetable plants and their fibres as building materials, Chapman and Hall, London (1990) 139-149. 
[7] A.O. Olorunnisola, Strength and water absorption characteristics of cement-bonded particleboard produced from coconut husk, Journal of Civil Engineering Research and Practice 3-1 (2006) 41 - 49. https://doi.org/10.4314/jcerp.v3i1.29150

[8] Information on: https://agriculturenigeria.com/farming.

[9] R.A.M. Sujuthi, K.C. Liew, Properties of bioplastic sheets made from different types of starch incorporated with recycled newspaper pulp, Transactions on Science and Technology, 3$1 \& 2$ (2016) $257-264$.

[10] O.G. Agbabiaka, I.O. Oladele, O.O Daramola, Mechanical and Water Absorption Properties of Alkaline Treated Coconut (cocosnucifera) and Sponge (acanthus montanus) Fibers Reinforced Polypropylene Composites, American Journal of Materials Science \& Technology, 4-2 (2015) 84-92. https://doi.org/10.7726/ajmst.2015.1007

[11] F. J.Aranda-Garcia, R. Gonzalez-Nunez, C.F Jasso-Gastinel, E. Mendizabal, Water absorption and thermomechanical characterization of extruded starch/poly (lactic acid)/agave bagasse fiber bioplastic composites. International Journal of Polymer Science, article ID 343294. https://doi.org/10.1155/2015/343294

[12] Information on: https://www.creativemechanisms.com/blog/everything-you-need-to-knowabout-bioplastics. 